\title{
PRECIPITATION FROM SPACE Advancing Earth System Science
}

\author{
by Paul A. Kucera, Elizabeth E. Ebert, F. Joseph Turk, Vincenzo Levizzani, Dalia Kirschbaum,
} Francisco J. Tapiador, Alexander Loew, and M. Borsche

The growth of long-term space-based precipitation datasets enables cross-disciplinary discoveries about hydrological and land processes, climate, atmospheric composition, and ocean freshwater budget and provides vital help in addressing societal issues.

0 $f$ the three primary sources of spatially contiguous precipitation observations (surface networks, ground-based radar, and satellitebased radar/radiometers), only the last is a viable source over ocean and much of Earth's land. As recently as 15 years ago, users needing quantitative detail of precipitation on anything under a monthly time scale relied upon products derived from geostationary satellite thermal infrared

AFFILIATIONS: KUCERA-National Center for Atmospheric Research, Boulder, Colorado; EBERT-Centre for Australian Weather and Climate Research, Bureau of Meteorology, Melbourne, Victoria, Australia; TURK-Jet Propulsion Laboratory, California Institute of Technology, Pasadena, California; LevizZANI-Institute of Atmospheric Sciences and Climate, National Research Council, Bologna, Italy; KIRSCHBAUM—NASA Goddard Space Flight Center, Greenbelt, Maryland; TAPIADORFaculty of Environmental Sciences and Biochemistry, University of Castilla-La Mancha, Toledo, Spain; LoEW AND BORSCHE-Max Planck Institute for Meteorology, Hamburg, Germany CORRESPONDING AUTHOR: Paul A. Kucera, Research Applications Laboratory, National Center for Atmospheric Research, 3450 Mitchell Lane, Boulder, CO 80307-3000 E-mail: pkucera@ucar.edu

The abstract for this article can be found in this issue, following the table of contents.

DOI:10.1175/BAMS-D-II-0017I.I

In final form 2 August 2012

(C)2013 American Meteorological Society
(IR) indices (e.g., Arkin and Meisner 1987). The Special Sensor Microwave Imager (SSM/I) passive microwave (PMW) imagers originated in 1987 and continue today with the Special Sensor Microwave Imager/Sounder (SSM/IS) sensor. The fortunate longevity of the joint National Aeronautics and Space Administration (NASA) and Japan Aerospace Exploration Agency (JAXA) Tropical Rainfall Measuring Mission (TRMM) is providing the environmental science community a nearly unbroken data record (as of December 2012, over 15 years) of tropical and subtropical precipitation processes. TRMM was originally conceived in the mid-1980s (Simpson et al. 1988) as a climate mission with relatively modest goals, including monthly averaged precipitation. TRMM data were quickly exploited for model data assimilation (Hou et al. 2001) and, beginning in 1999 with the availability of near-real-time data, for tropical cyclone warnings (Hawkins et al. 2001).

To overcome the intermittently spaced revisits from these and other low Earth-orbiting satellites, many methods to merge PMW-based precipitation data and geostationary satellite observations have been developed, such as the TRMM Multisatellite Precipitation Analysis (Huffman et al. 2007) and the Climate Prediction Center (CPC) morphing technique (CMORPH) (Joyce et al. 2004). The purpose of this article is not to provide a survey or assessment of these and other satellite-based precipitation datasets, which are well summarized in several recent articles 


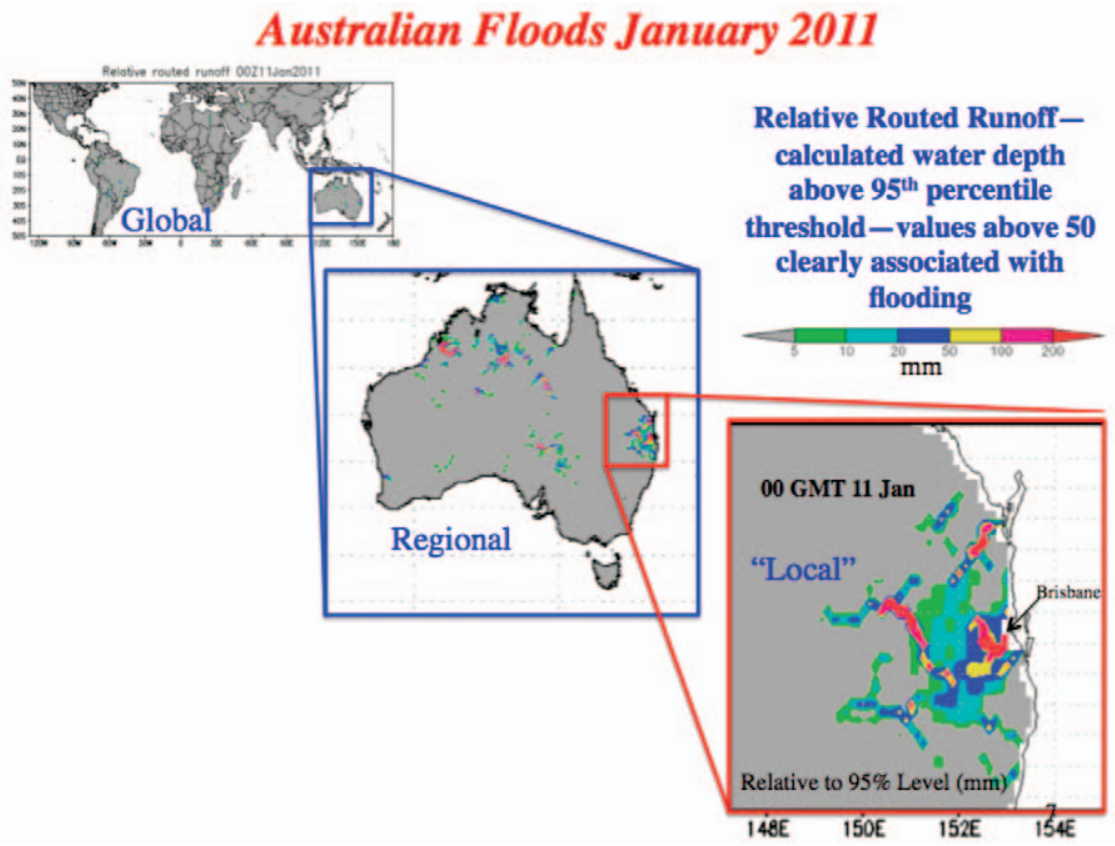

FIG. I. Water depth over 95th percentile of 12 -yr simulation of routed runoff as initial indicator of flooding in the Global Flood Monitoring System. Example of real-time results for Australian floods in January 2011. use various high-resolution precipitation products. The final section summarizes the future system for global precipitation processing.

Applications. Precipitation products are critical for the development of applications that address a variety of scientific and societal needs. It is difficult to discuss precipitation applications without proper consideration of the spatial and temporal scales of individual products, as well as their timeliness and veracity. The applications described below are by no means an exhaustive list but highlight the breadth of applications that have been developed through (Tapiador et al. 2012; Kidd et al. 2012; Kidd and Levizzani 2011; Dinku et al. 2010). Rather, the intent is to demonstrate how the availability and continuity of satellite-based precipitation data records is transforming the ways that scientific and societal issues related to precipitation are addressed, in ways that would not be otherwise possible. These developments have taken place in parallel with the growth of an increasingly interconnected scientific environment. Scientists from different disciplines can easily interact with each other via information and materials they encounter online and collaborate remotely without ever meeting each other in person. Likewise, these precipitation datasets are quickly and easily available via various data portals and are widely used. Within the framework of the NASA-JAXA Global Precipitation Measurement (GPM) (Hou et al. 2008) mission, these applications will become increasingly interconnected.

We emphasize that precipitation observations by themselves provide an incomplete picture of the state of the atmosphere. For example, it is unlikely that a richer understanding of the global water cycle will be possible by standalone missions and algorithms but must also involve some component of data assimilation (Michaelides et al. 2009), where model analyses of the physical state are constrained alongside multiple observations (e.g., precipitation, evaporation, radiation). The next section provides examples extracted from the many applications that incorporation of satellite-based precipitation datasets.

FLOODING AND LANDSLIDES. Floods and landslides represent some of the most devastating hydrometeorological natural disasters on the Earth, resulting in extensive economic damage and fatalities that affect nearly every country in the world. Despite their broad impacts, characterizing the frequency, severity, and occurrence of such events has been primarily limited to regional or local analyses due to the dearth of rainfall gauges and the spatial scale of existing landslide and flood models. Recent research has sought to use satellite rainfall estimates from TRMM to inform the spatial and temporal distribution of flooding and landslides at the global scale (Hong et al. 2006, 2007b, 2010). These modeling efforts provide the foundation for a better understanding of the behavior, variability, and potential forecast potential of floods and rainfall-triggered landslides.

A global flood monitoring system initially developed by Hong et al. (2007a, 2010) and evaluated by Yilmaz et al. (2010) has been improved with a physically based hydrological model (Wang et al. 2011). This global flood monitoring system (GFMS) integrates TRMM Multisatellite Precipitation Analysis (TMPA) precipitation estimates, readily available geospatial datasets, and a hydrological model running at a $1 / 8^{\circ}$ latitude-longitude resolution. A 12-yr retrospective simulation is used to develop a grid of 95th percentile 
routed runoff that serves as a starting point for flood detection and monitoring (Fig. 1). Evaluation of this improved GFMS against a global flood event database (Wu et al. 2012) indicates a probability of detection (POD) of $\sim 0.7$ and a false alarm rate (FAR) of $\sim 0.6$ for floods over three days in duration. The evaluation results also suggest that basins with large dams have significantly higher FAR values, indicating the need to take into account their effects. In a similar effort, JAXA has supported the development of the Global Flood Alert System (GFAS) to support flood forecasting and warning worldwide. The system is hosted by the International Flood Network (IFNet; http://gfas internationalfloodnetwork .org/gfas-web/), which provides global and regional rainfall maps of rainfall and rainfall exceedance for 5- and 10-yr return periods. Other regional and global flood modeling research studies (e.g., Lettenmaier et al. 2006; Pan et al. 2010) have focused on developing hydrologic model routing schemes to improve prediction of flood onset and dissipation. These schemes have been developed and tested for several basins in the United States and Africa.

Rainfall-triggering landslide modeling activities have primarily utilized rainfall gauge information and can generally be divided into three categories: static approaches to characterize the spatial distribution of potentially susceptible areas; regional empirical approaches that evaluate the intensity and duration of rainfall in potentially triggering a landslide event; and sitespecific deterministic approaches where a slopestability model is applied to characterize the specific 5 Aug 201 I. nature of landslide processes at the hillslope scale. A prototype landslide algorithm developed by Hong et al. $(2006,2007 b)$ couples a static landslide susceptibility map with TMPA rainfall information to indicate areas that may be prone to landslides at the global scale. The algorithm is updated every three hours and provides landslide nowcasts from $50^{\circ} \mathrm{N}$ to $50^{\circ} \mathrm{S}$ at a $0.25^{\circ} \times 0.25^{\circ}$ pixel resolution. Evaluation of this prototype system suggests that the current susceptibility map and rainfall thresholds employed show some skill (POD ranged from a maximum of $22 \%$
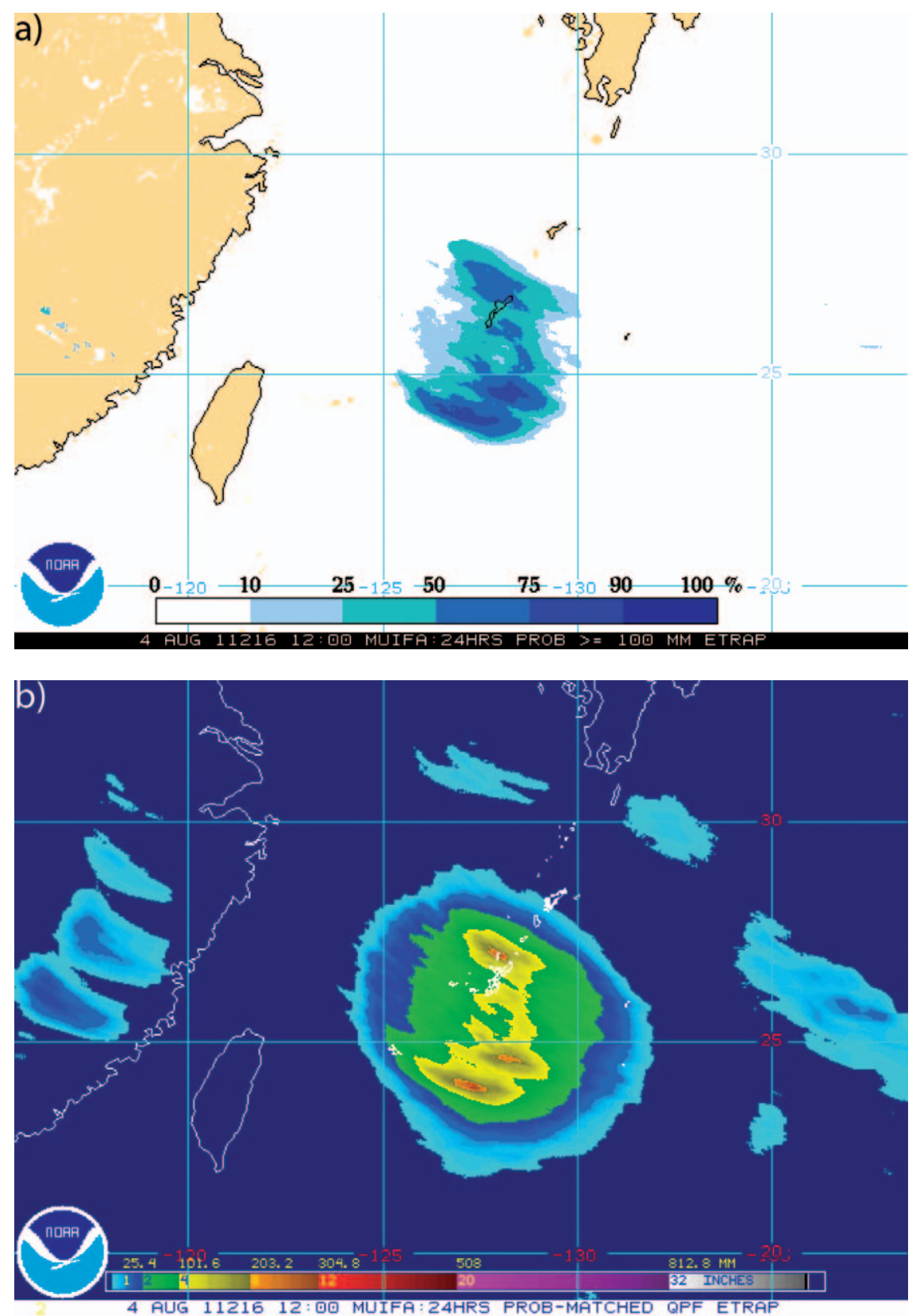

FIG. 2. The eTRaP forecast of (a) probability of 24-h precipitation exceeding $100 \mathrm{~mm}$ and (b) 24-h rain accumulation in Typhoon Muifa, valid at I200 UTC 
for a 1-day temporal window and a minimum of $6 \%$ for a 7-day temporal window for the two years evaluated) in identifying landslide-prone regions but also serve to over or under estimate landslide nowcasting in several regions (Kirschbaum et al. 2009). Results also indicate that this system would be enhanced if precipitation characteristics of landslide-triggering events are considered within different climatologic zones to better account for the variability of rainfall intensity and duration (Kirschbaum et al. 2011). The higher-resolution precipitation observations and corresponding surface conditions would better resolve localized landslide hazards (e.g., topography, soil conditions) that are not observed in the coarse-scale global landslide algorithm.

In the above-mentioned flood and landslide modeling approaches, the near-real-time accessibility and global availability of the TRMM and future GPM products enables rapid hazard assessment and potential flood and landslide forecasting. Real-time products can be accessed online (at http://trmm.gsfc.nasa.gov /publications_dir/potential_flood_hydro.html). While the current spatial resolution of the TRMM products generally restricts their application to the scale of the TRMM products $\left(0.25^{\circ} \times 0.25^{\circ} ; 3 \mathrm{~h}\right)$, results indicate that using satellite-based precipitation products enables the characterization of flood and landslide hazards at the global scale, filling a much-needed gap in the hazard assessment community. As the resolution of the precipitation products improve, the model resolution should also improve, providing better information of flood and landslide hazards at finer scales.

\section{ENSEMBLE TROPICAL RAINFALL} POTENTIAL. Heavy rains associated with landfalling tropical cyclones frequently trigger floods that cause millions of dollars of damage and lost lives. To provide observations-based forecast guidance for tropical cyclone (TC) heavy rain, Kidder et al. (2005) developed the Tropical Rainfall Potential (TRaP), an extrapolation forecast generated by accumulating rainfall estimates from microwave sensors over a $24-\mathrm{h}$ period as the storm is translated along the forecast track. TRaP aims to predict the maximum rainfall at landfall, as well as the spatial pattern of precipitation, and has been shown to have similar or better skill than short-range numerical weather prediction models (Ferraro et al. 2005; Ebert et al. 2005).

One key aspect where satellite-based precipitation products excel is their relative skill in the location and timing of precipitation. The issue of assimilating precipitation observations (or precipitation-affected satellite radiances) into weather prediction models is yet an open topic of investigation (Bauer et al. 2011). A recent innovation has been to combine the TRaP forecasts from multiple sensors and various start times into an ensemble TRaP product known as eTRaP (Ebert et al. 2011). The ensemble approach provides not only more accurate quantitative precipitation forecasts, including more skilful maximum rainfall amount and location, but also probabilistic forecasts of rainfall exceeding various thresholds that decision makers can use to make critical risk assessments. Ebert et al. (2011) showed that eTRaP probabilistic forecasts have useful skill but the grid-scale probabilities are biased high when compared to observations and should be interpreted in a broader spatial context. Efforts to calibrate the probabilistic forecasts from eTRaP are underway. Figure 2 shows an example of an eTRaP forecast for Typhoon Muifa as it passed south of Okinawa on 4 August 2011. It predicted $50 \%$ probability of exceeding $100 \mathrm{~mm}$ over northern Okinawa, with a maximum 24 -h rainfall of about $300 \mathrm{~mm}$. The measured 24-h rainfall at 1200 UTC 5 August was $147.5 \mathrm{~mm}$ at Oku on the northern tip of Okinawa and $313.5 \mathrm{~mm}$ at Nago in the center of the island. While the location of the maximum rain in the eTRaP forecasts was spatially displaced by about $50 \mathrm{~km}$, it would have provided useful guidance for forecasters and emergency managers.

The eTRaPs are computed four times daily for all named tropical cyclones and storms and can be viewed online (at www.ssd.noaa.gov/PS/TROP/etrap.html).

\section{GLOBAL HIGH-RESOLUTION TERRES- TRIAL SURFACE HEAT AND MOISTURE} FLUX ESTIMATES. Evapotranspiration is one of the major fluxes in the hydrological cycle. The latent heat flux (LE) amounts to about $80 \mathrm{~W} \mathrm{~m}^{-2}$ (Trenberth et al. 2009) on a global scale (ocean and land) and is therefore the largest single heat source for the atmosphere with high relevance in weather and global water cycle dynamics (Dirmeyer 2006). However, existing datasets of surface heat fluxes are still highly uncertain. The Global Energy and Water Cycle Experiment (GEWEX) LandFluxEval project focused on the comparison of a variety of different existing LE products over land. A spread of $20 \mathrm{~W} \mathrm{~m}^{-2}$ (sigma $=5 \mathrm{~W} \mathrm{~m}^{-2}$ ) was identified between different existing datasets, with an all-product global mean value of $45 \mathrm{~W} \mathrm{~m}^{-2}$ for the land surface latent heat flux (Jiménez et al. 2011; Mueller et al. 2011). These uncertainties are comparably large when compared to global-scale heat fluxes and correspond to roughly one-third of the annual global sensible heat flux of $17 \mathrm{~W} \mathrm{~m}^{-2}$ (Trenberth et al. 2009). 
The availability of accurate global precipitation data is one major driver for an accurate determination of surface heat fluxes as it is major input for land surface models used to estimate surface heat fluxes. Currently, only satellite data can provide precipitation estimates at the global scale with sufficient temporal resolution. Miralles et al. (2011) used CMORPH (Joyce et al. 2004) and the Global Precipitation Climatology Program (GPCP) (Huffman et al. 2009) daily precipitation for the generation of a global dataset of evapotranspiration with a spatial resolution of $0.25^{\circ}$.

M. Borsche and A. Loew (2012, personal communication, hereafter $\mathrm{BL}$ ) have analyzed the impact of using satellite-based precipitation estimates for the estimation of surface latent heat fluxes using spatially and temporally high-resolution geostationary satellite data for surface radiation fluxes and TMPA for precipitation estimates (Knapp et al. 2011). They analyzed the impact of replacing rain gauge-based precipitation data by TMPA 3-hourly rainfall intensities (Huffman et al. 2007) for the estimation of surface latent heat fluxes through a series of experiments and validating the estimated surface heat fluxes by in situ measurements from FluxNet (Aubinet et al. 1999; Baldocchi 2008). Figure 3 shows the seasonal mean latent heat flux as estimated from geostationary observations using TMPA precipitation as forcing. Figure 4 shows the correlation and root-mean-square error (RMSE) of estimated and observed latent heat fluxes for 19 different FluxNet stations from different biomes using either only station data as a forcing or satellite-based forcing. The RMSE is 56.8 and $63.6 \mathrm{~W} \mathrm{~m}^{-2}$ at hourly time scales for station and satellite-based forcing, respectively. At daily time scales, the RMSE is 39.0 (43.1) $\mathrm{W} \mathrm{m}^{-2}$ for station (satellite) forcing. While the errors for the satellite-based LE estimates are slightly higher than for the station forcing, BL show that this increase in uncertainty is mainly due to uncertainties in the radiation forcing and less because of uncertainties in the available TMPA precipitation data.

A related application involves the close correspondence between soil moisture and precipitation. Soil moisture controls the partitioning of precipitation into infiltration, surface runoff, and evaporation/ transpiration from land surfaces. The precipitation time history also modulates the microwave surface emissivity, an important consideration for over-land precipitation estimation (Li et al. 2010). Comparisons of surface emissivity retrievals together with the previous-time precipitation totals are an indirect yet qualitative way to validate emissivity retrievals over rainaffected surfaces and to devise improved over-land precipitation retrievals (Ferraro et al. 2013). Another application that uses satellite precipitation products to compute representative land surface conditions (e.g., soil moisture) is the Modern-Era Retrospective Analysis for Research (MERRA) project (Reichle et al. 2011), which is generated by the NASA Global Modeling and Assimilation Office (GMAO; http:// gmao.gsfc.nasa.gov/). MERRA focuses on the assimilation of in situ and remote sensing data into numerical models to provide a representative global atmospheric (e.g., precipitation, temperature, humidity) and land surface dataset (e.g., soil moisture, snow, runoff). The MERRA products are then used for a variety of applications such as the study of land surface water budgets including floods, droughts, soil moisture processes. Having accurate satellite precipitation data increases the usefulness of datasets such as MERRA by reducing the uncertainty of the generated fields.

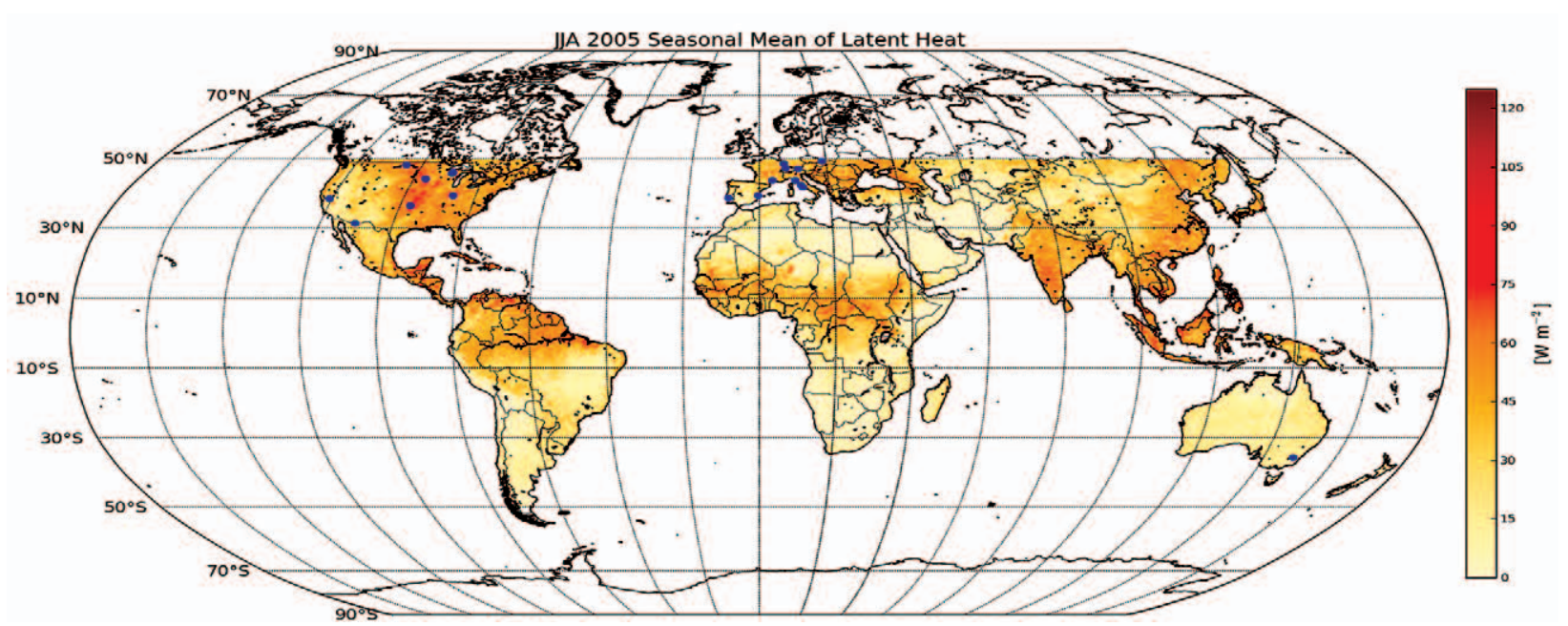

Fig. 3. Seasonal (JJA) high-resolution $(5 \mathrm{~km})$ mean latent heat derived from geostationary satellite data using TMPA precipitation data (BL). 

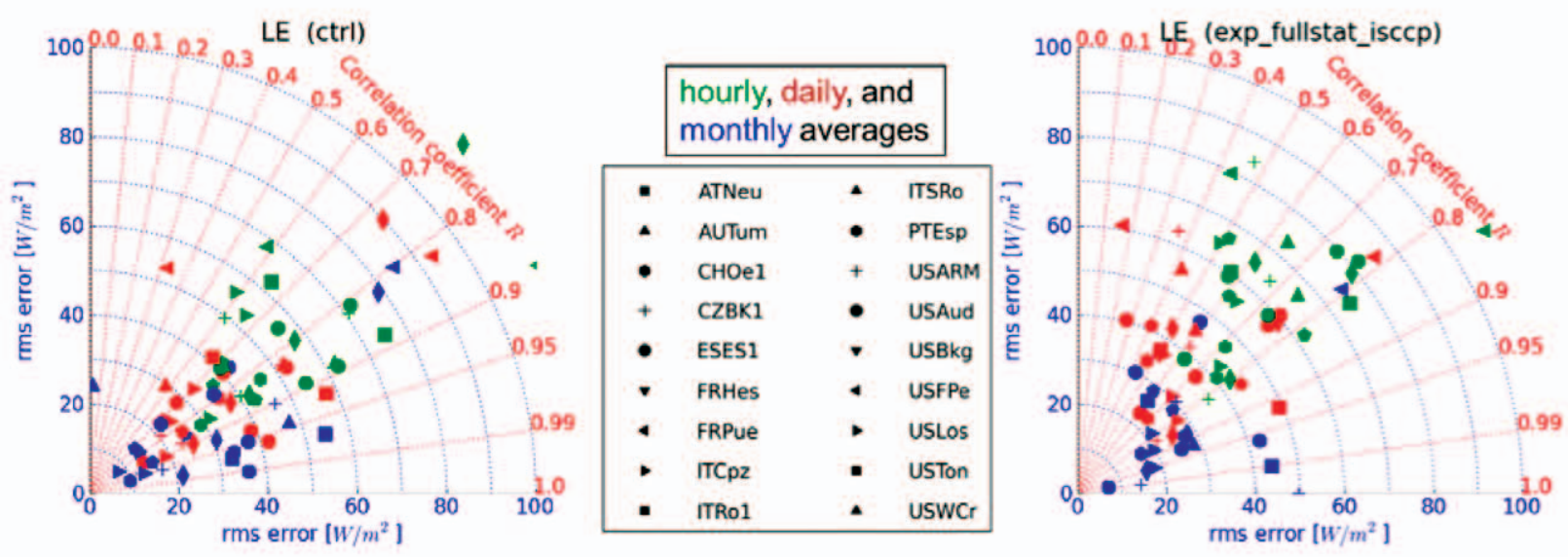

FIG. 4. Multiannual RMSE difference and correlation of latent heat flux obtained from (left) station forcing and (right) satellite forcing using different FluxNet stations as a reference. Different colors correspond to different temporal aggregation (BL).

ATMOSPHERIC AEROSOLS. Aerosol particles introduce one of the largest uncertainties in model-based estimates of direct and indirect forcing on climate. Aerosol processes in models such as transport, source, and sinks typically reply on modelderived meteorology and are assimilated into operational aerosol prediction models (Zhang et al. 2008). However, the processes are sensitive to errors in the underlying simulation that propagate through the system. Precipitation, as one of the basic meteorological elements in an aerosol model, has a large effect on aerosol load since it is the primary sink. It is expected that precipitation area coverage is more important than precipitation intensity in affecting model aerosol optical thickness (AOT), but a potential implication is that excessive light precipitation in models (Sun et al. 2006) may overscavenge aerosol particles.

Xian et al. (2009) found that light rain over large areas using the Navy Operational Global Atmospheric Prediction System (NOGAPS) forecast model removed significantly more aerosol particles than the more realistic heavy rain in small areas found in the Naval Research Laboratory (NRL) blended satellite (NRLBlend) precipitation product (Turk and Miller 2005), even though the total precipitation was nearly the same in the two schemes. Figure 5 shows the smoke AOT resulting from the use of the NRL-Blend precipitation in the tropics on the left and the ratio of smoke AOT NRL-Blend run over NOGAPS run on the right for four burning seasons. When NRL-Blend precipitation is used instead of NOGAPS, smoke AOT in general increases in the tropics for all seasons including the least active burning period, November through January. During February through April, which is the major burning period for peninsular Southeast
Asia, the increase in AOT with the NRL-Blend run is about a factor of 2 on average and up to 2.8 over the Malay Peninsula. Thus, although on seasonal time scales current numerical models could approximately capture the real-world precipitation pattern, there might be differences in regional AOT due to differences in short-time-scale precipitation. This could significantly affect wet deposition of aerosols and thus modeled AOT in regions of convection. Other shorttime-scale problems, such as trying to infer aerosol concentrations in the vicinity of convective cells observed by satellite, may also be challenged by the model's precipitation scheme. Aerosol particles may be overly scavenged out in the model by the time the air mass reaches the observed cell (Turk and Xian 2012).

\section{MODEL ASSESSMENT AND VALIDATION.}

Unlike prognostic variables such as temperature and moisture, precipitation is a diagnosed quantity in most weather and climate models. Owing to the methods whereby precipitation is triggered, it is important to verify not only the model-derived precipitation quantitatively (Ebert et al. 2007) but also the capability of the model to place precipitation in the right place at the right time. In this regard, satellite precipitation datasets are the pillars for validating the performance of numerical models such as regional climate models (RCMs), which are dynamically downscaling tools used to improve the spatial resolution of outputs from reanalyses and global climate models (GCMs). Over land, several studies have shown that RCMs provide consistent estimates of precipitation after accounting for known uncertainties in the reference data (Tapiador 2010). Gauge data, such as the Climate Research Unit (CRU), 
GPCP, the CPC Merged Analysis of Precipitation (CMAP), and the Global Precipitation Climatology Center (GPCC) databases have been compared with RCM simulations over Europe both in terms spatially reproducing the climatology and the probability distributions of precipitation (Tapiador et al. 2009) and in terms of capturing the phase and power of precipitation cycles (Tapiador and Sánchez 2008), obtaining consistent results. Such intercomparison/validation of RCMS is directly relevant for applications such as hydropower since RCMs outputs are used to gauge the future availability of water for this renewable energy (Tapiador et al. 2009; Tapiador et al. 2012).

Over the oceans, however, there are no or few rain gauges available, so satellite observations are needed to validate models. Measuring and modeling oceanic precipitation is important since this geophysical parameter is required for a full understanding of the Earth system, including the closure of the hydrological cycle. Comparisons of RCM outputs with satellite-based databases (Fig. 6) such as the GPCP (Adler et al. 2003) are instrumental to evaluate the performances of the RCMs over the oceans and thus to improve the models.

SOCIETAL IMPACT MONITORING. Soil moisture controls the partitioning of precipitation into infiltration and surface runoff, and satellite precipitation records provide observations to better understand the spatiotemporal link between precipitation and soil moisture. Many of the same PMW sensors used for precipitation estimation can be adapted for use in estimating soil moisture and vegetation water content ( $\mathrm{Li}$ et al. 2010). Soil moisture products are used to augment gauge sparse areas to improve short-term precipitation estimates (Crow et al. 2009). Satellite precipitation estimates have been critical for monitoring of drought in Africa, where surface observations are sparse. For example, Fig. 7 shows the 2011 precipitation anomaly for March-May for the southern two-thirds of Africa compared to the 2000-09 climatology. The map shows areas that were prone to drought (e.g., East Africa) and/or flooding (e.g., South Africa) during this period. In a changing climate scenario, droughts are perhaps the less known part of the water cycle especially in those areas that are more exposed than others to the drought risk, such as the Horn of Africa (Lyon and DeWitt 2012).

To address the issues of water availability (or lack of) and predictions of future water scarcity in the context of global climate change, the project Global Water Monitoring Information Service (GLOWASIS) of the Seventh Framework Programme of the European Commission uses satellite rainfall estimations for the hydrological monitoring and forecasting in the context of the Global Monitoring for Environment and Security (GMES) initiative (http://glowasis .eu/). Because accurate estimates of water availability in remote areas such as Africa are difficult to obtain but are critical for monitoring crop production and
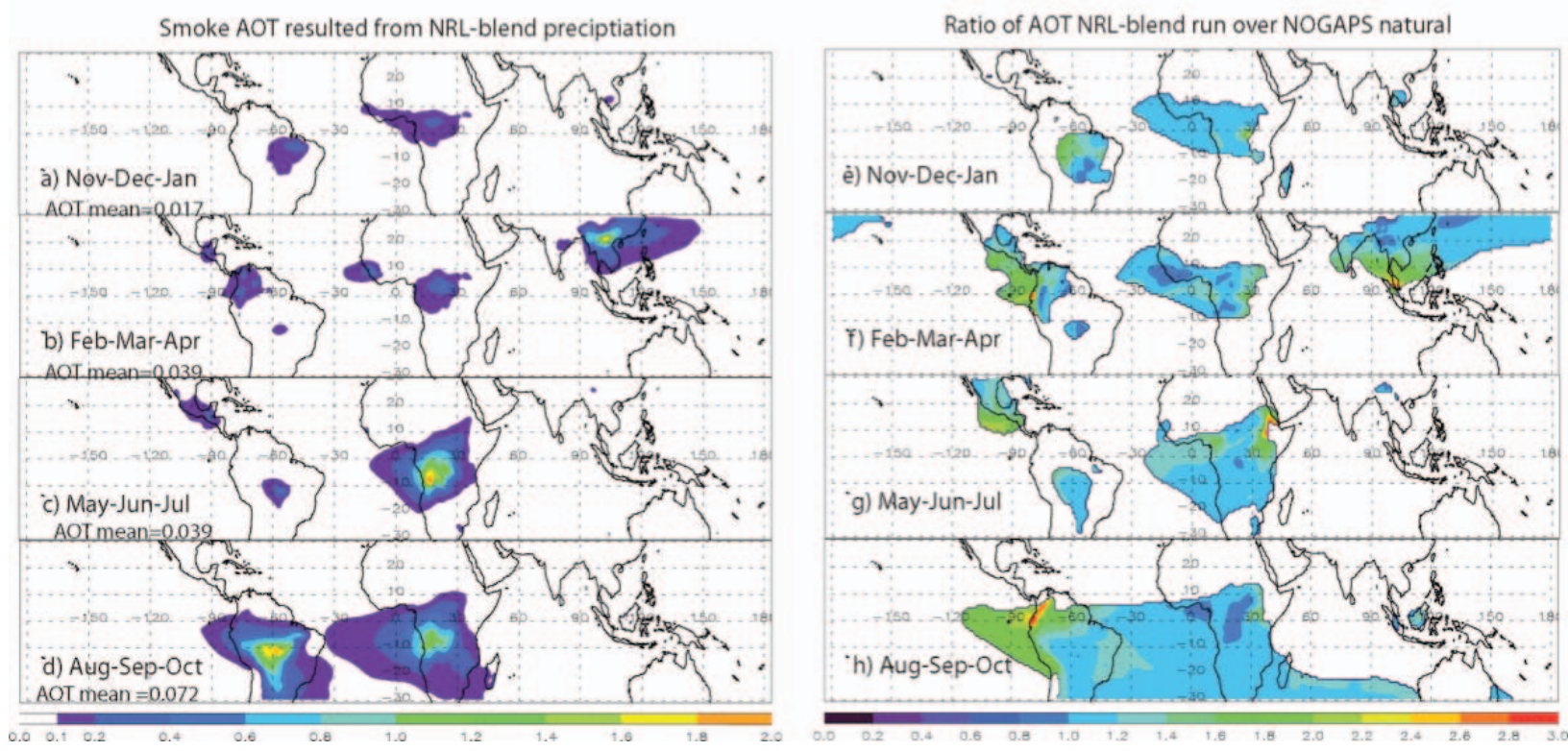

FIG. 5. (left) Smoke AOT resulted from NRL-blend precipitation for four biomass burning periods in 2007. (right) Ratio of smoke AOT resulted from NRL-blend precipitation over smoke AOT resulting from NOGAPS precipitation for four biomass burning periods in 2007 (colored for regions with AOT >0.05 in NRL-blend run) (Xian et al. 2009). 
associated issues with food security, GLOWASIS has focused on improving the quantification of errors in water budget components, global models, and spacebased global precipitation measurements. This effort is in attempt to increase the accuracy of monthly forecasts of water availability. The GLOWASIS project is attempting to meet the challenges of addressing the monitoring water availability by combining models with observations (e.g., satellite precipitation products) through improved algorithms. These resources are available to regional decision makers through open access to the products. The GLOWASIS project is one example of an application the requires satellite precipitation products to improve the monitoring to help improve in the preparation of regional to global impacts on society such as droughts and floods.

CONCLUSIONS. This article has highlighted several cross-disciplinary Earth system science investigations that have been advanced through the availability of consistent global precipitation records. An increasing number of applications are dependent upon the availability of near-real-time information that may not be science-quality data; others require science-quality data records that are hosted by distributed data archive centers. The planned and
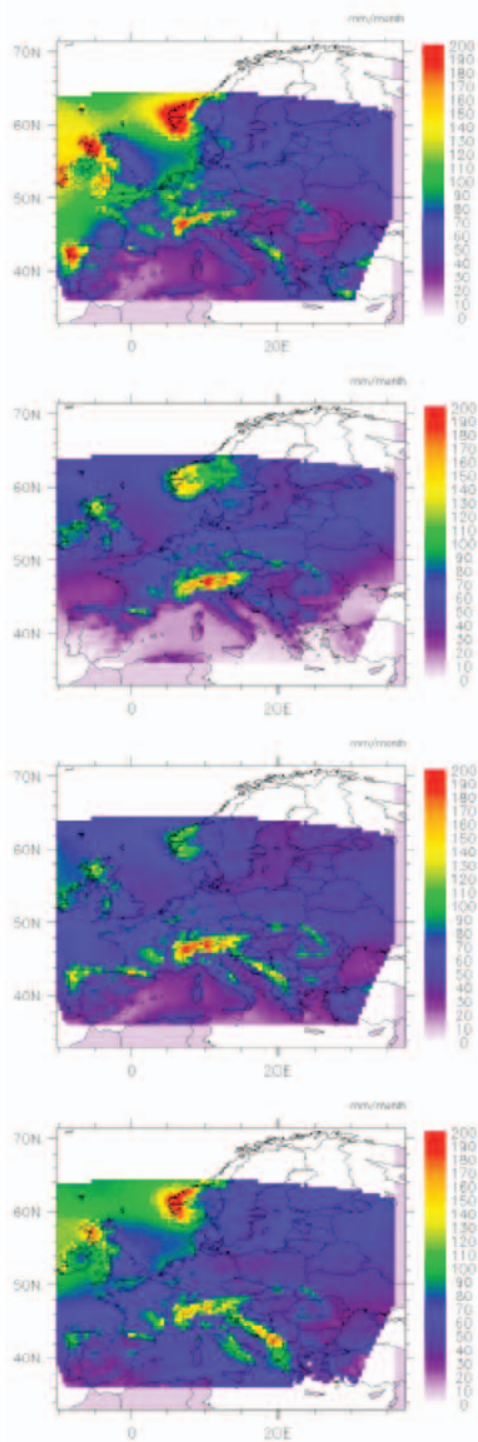

RCMs
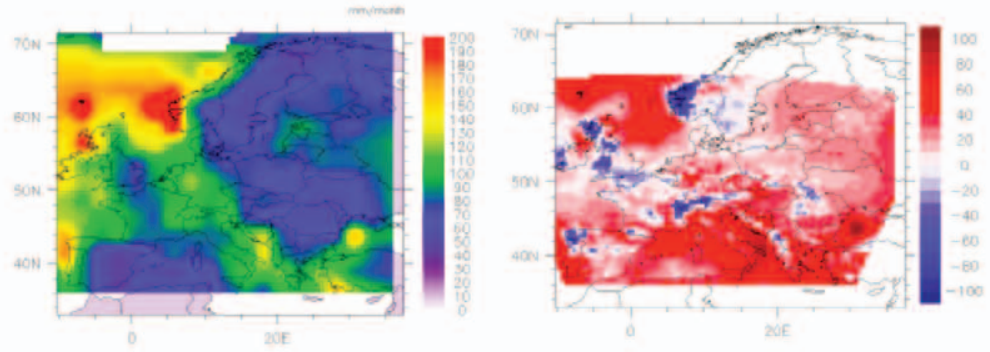

DJF
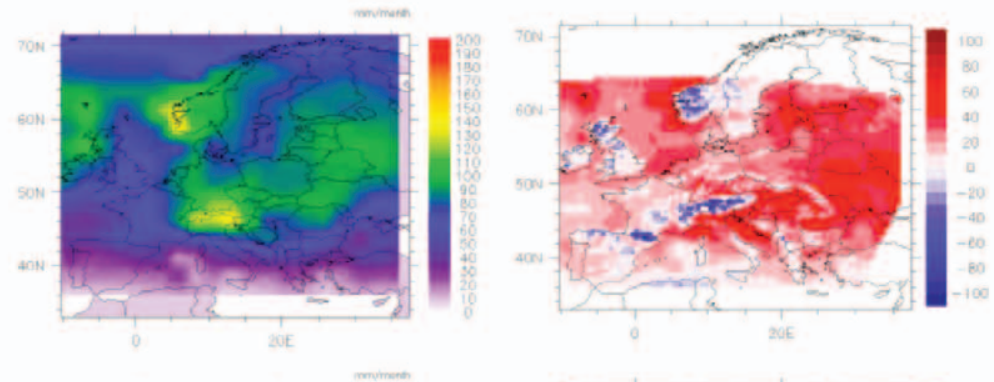

MAM

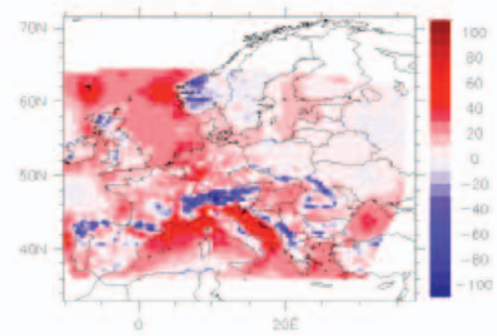

JJA

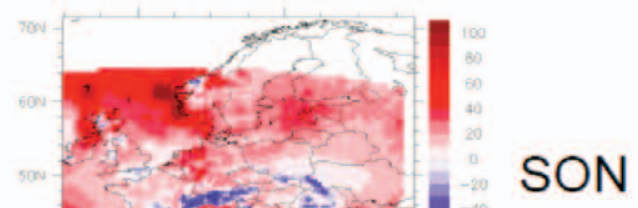

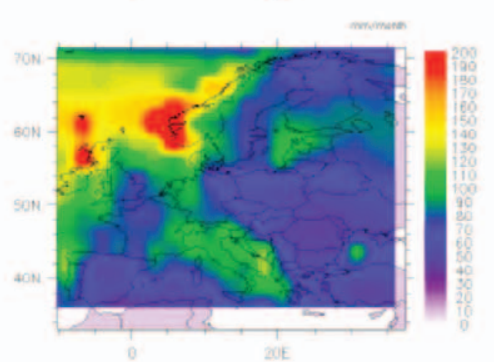

GPCP
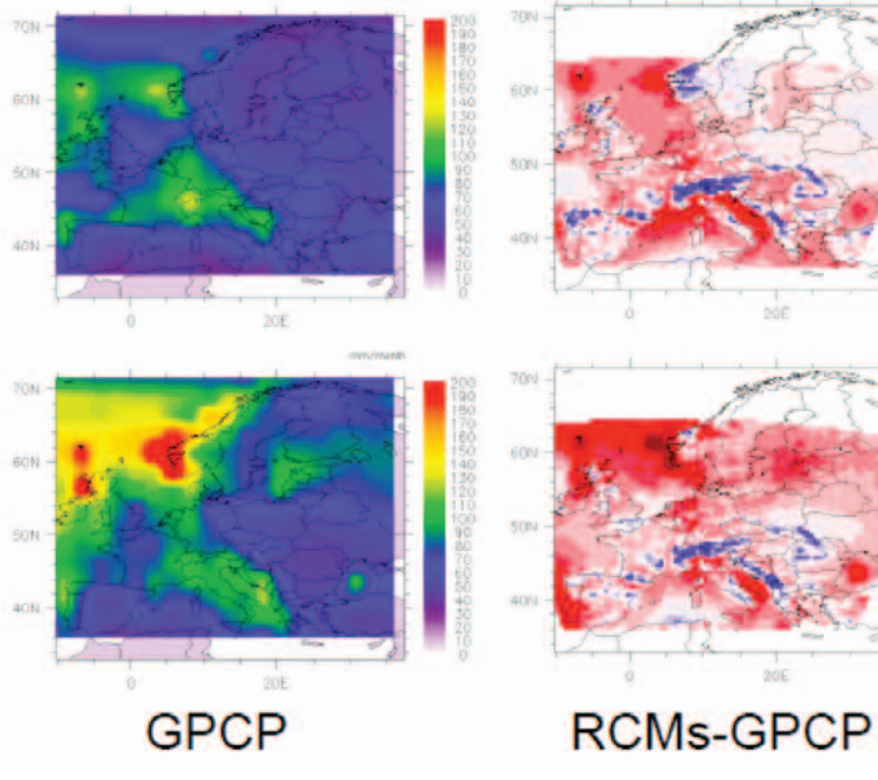

FIG. 6. Comparison of the ensemble average of eight $\mathrm{RCMs}\left(0.5^{\circ}\right.$ resolution $)$ with a satellite-based observational database (GPCP; $2.5^{\circ}$ resolution) over Europe, for present-day climatologies. (right) The difference plots illustrate the contrasting performances of the RCMs depending on season and on location. Note the different spatial resolution of the data, which affects maxima and minima. 
future satellite missions are critical for the continued advancement of precipitation products and, subsequently, applications that utilize the precipitation products. These new satellite missions will overlap with existing satellite missions to provide consistent, long-term data records.

The global constellation of Earth observing systems for precipitation is constructed with a variety of instruments, low Earth-orbiting microwave imagers and sounders, radar, and geostationary Earthorbiting imagers. Community efforts such as the Global Satellite Intercomparison (GSICS; Goldberg et al. 2011) are imperative to establish self-consistent data records across satellite lifetimes, sensor revisions, etc. The space-based precipitation observing system was recently enhanced by the deployment of the joint French Centre National d'Études Spatiales (CNES) and Indian Space Research Organization (ISRO) Megha-Tropiques satellite (orbiting asynchronously in a $20^{\circ}$ inclination), the first of an advanced technology microwave sounder (ATMS) onboard the Suomi National Polar Orbiting Partnership (NPP) spacecraft, JAXA's Global Change Observing Mission$W(G C O M-W)$, and the Chinese Meteorological Agency (CMA) FY-3 series. Currently, TRMM is well beyond its expected life but will continue to collect

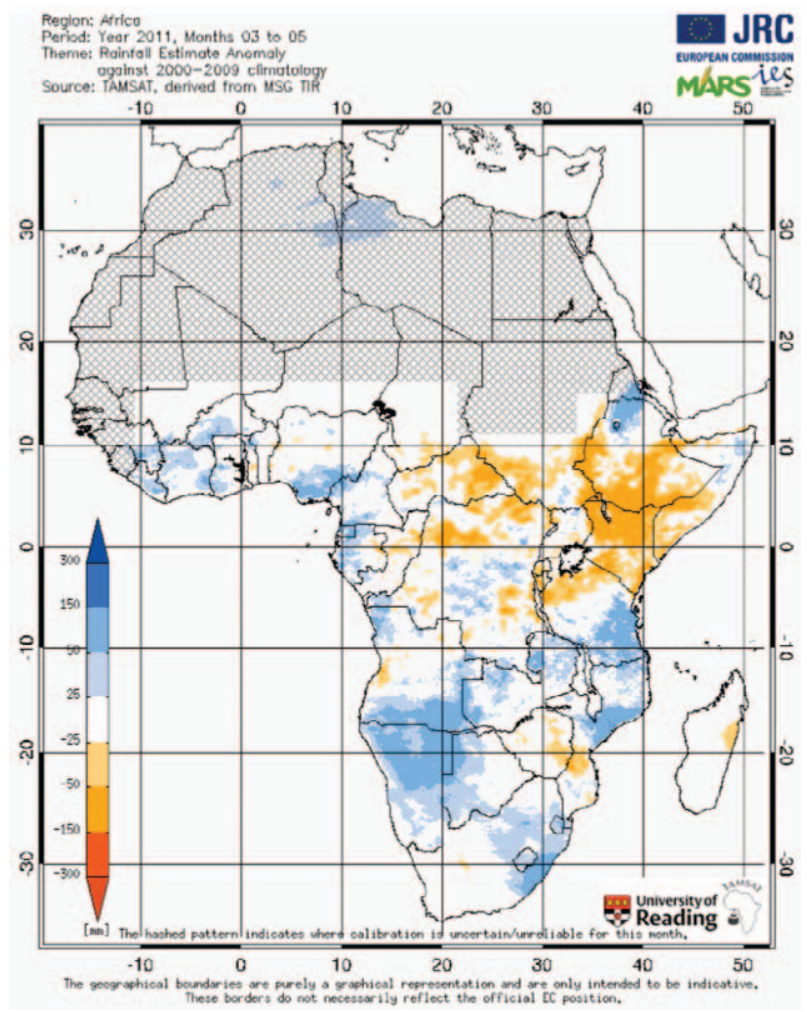

Fig. 7. African 20II MAM rainfall anomaly relative to 2000-09 climatology. observations until it exhausts its station-keeping fuel supply (largely determined by the solar cycle), after which it will begin its gradual deorbit. However, there is a possibility that TRMM will overlap with the upcoming (2014) GPM mission, providing an opportunity for a seamless, long-term data record. The core GPM spacecraft will deploy an advanced dual-frequency $(\mathrm{Ku} / \mathrm{Ka}$ band) precipitation radar (DPR) orbiting at a $65^{\circ}$ orbit inclination, providing coverage at high latitudes not overflown by TRMM for estimation of snowfall and light precipitation. The GPM core satellite will be joined by the NASA Soil Moisture Active Passive (SMAP) satellite in 2015, enabling complementary measurements and synergistic analyses between surface soil moisture state and precipitation (Entekhabi et al. 2010).

A future global precipitation processing system will likely encompass multiple satellite sensors (active and passive), ground observations, and radar networks to obtain improved spatial and temporal resolution with reduced uncertainties. For example, flash flood guidance systems need short-time-scale, high-resolution precipitation fields, especially in remote regions, to improve flash flood forecasting on a basin scale. Societal applications such as drought monitoring, soil moisture/crop monitoring, and health monitoring (e.g., meningitis outbreaks in Africa) can benefit from satellite precipitation datasets. Large-scale applications such as regional climate modeling will benefit from the higher-resolution precipitation data when evaluating potential climate impacts at a regional scale.

ACKNOWLEDGMENTS. This paper was facilitated through numerous discussions with International Precipitation Working Group (IPWG; www.isac.cnr.it/ ipwg /IPWG.html) members. We acknowledge Dr. Peng Xian from the Naval Research Laboratory, Monterey for her assistance with the atmospheric composition section. F. J. Tapiador acknowledges projects PPII10-0162-5543 and CGL2010-20787-C02-01. This paper is dedicated to David I. F. Grimes (1951-2011), who was an advocate for development and outreach of precipitation products to meet societal needs in Africa.

\section{REFERENCES}

Adler, R. F., and Coauthors, 2003. The version-2 Global Precipitation Climatology Project (GPCP) monthly precipitation analysis (1979-present). J. Hydrometeor., 4, 1147-1167.

Arkin, P. A., and B. N. Meisner, 1987: The relationship between large-scale convective rainfall and cold 
cloud over the Western Hemisphere during 1982-84. Mon. Wea. Rev., 115, 51-74.

Aubinet, M., and Coauthors, 1999: Estimates of the annual net carbon and water exchange of forests: The EUROFLUX methodology. Adv. Ecol. Res., 30, 113-175.

Baldocchi, D., 2008: Breathing of the terrestrial biosphere: Lessons learned from a global network of carbon dioxide flux measurement systems. Aust. J. Bot., 56, 1-26.

Bauer, P., G. Ohring, C. Kummerow, and T. Auligne, 2011: Assimilating satellite observations of clouds and precipitation into NWP models. Bull. Amer. Meteor. Soc., 92, ES25-ES28.

Crow, W. T., G. J. Huffman, R. Bindlish, and T. J. Jackson, 2009: Improving satellite-based rainfall accumulation estimates using spaceborne surface soil moisture retrievals. J. Hydrometeor., 10, 199-212.

Dinku, T., F. Ruiz, S. J. Connor, and P. Ceccato, 2010: Validation and intercomparison of satellite rainfall estimates over Colombia. J. Appl. Meteor. Climatol., 49, 1004-1014.

Dirmeyer, P., 2006: The hydrologic feedback pathway for land-climate coupling. J. Hydrol., 7, 857-867.

Ebert, E., S. Kusselson, and M. Turk, 2005: Validation of NESDIS operational Tropical Rainfall Potential (TRaP) forecasts for Australian tropical cyclones. Aust. Meteor. Mag., 54, 121-135.

— J. J. E. Janowiak, and C. Kidd, 2007: Comparison of near-real-time precipitation estimates from satellite observations and numerical models. Bull. Amer. Meteor. Soc., 88, 47-64.

—, M. Turk, S. J. Kusselson, J. Yang, M. Seybold, P. R. Keehn, and R. J. Kuligowski, 2011: Ensemble Tropical Rainfall Potential (eTRaP) forecasts. Wea. Forecasting, 26, 213-224.

Entekhabi, D., and Coauthors, 2010: The Soil Moisture Active and Passive (SMAP) mission. Proc. IEEE, 98, 704-716, doi:10.1109/JPROC.2010.2043918.

Ferraro, R., and Coauthors, 2005: The Tropical Rainfall Potential (TRaP) technique. Part II: Validation. Wea. Forecasting, 20, 465-475.

__ and Coauthors, 2013: An evaluation of microwave land surface emissivities over the continental United States to benefit GPM-era precipitation algorithms. IEEE Trans. Geosci. Remote Sens., 51, 378-398, doi:10.1109/TGRS.2012.2199121

Goldberg, M., and Coauthors, 2011: The Global Spacebased Inter-Calibration System. Bull. Amer. Meteor. Soc., 92, 467-475.

Hawkins, J. D., T. F. Lee, J. Turk, C. Sampson, J. Kent, and K. Richardson, 2001: Real-time internet distribution of satellite products for tropical cyclone reconnaissance. Bull. Amer. Meteor. Soc., 82, 567-578.

Hong, Y., R. Adler, and G. Huffman, 2006: Evaluation of the potential of NASA multi-satellite precipitation analysis in global landslide hazard assessment. Geophys. Res. Lett., 33, doi:10.1029/2006GL028010.

$\longrightarrow,-$ F. Hossain, S. Curtis, and G. J. Huffman, 2007a: A first approach to global runoff simulation using satellite rainfall estimation. Water Resour. Res., 43, W08502, doi:10.1029/2006WR005739.

- , - - and G. Huffman, 2007b: Use of satellite remote sensing data in the mapping of global landslide susceptibility. Nat. Hazards, 43, 245-256, doi:10.1007/s11069-006-9104-z.

,-- , and — 2010: Applications of TRMMbased multi-satellite precipitation estimation for global runoff prediction: Prototyping a global flood monitoring system. Satellite Rainfall Applications for Surface Hydrology, F. Hossain and M. Gebremichael, Eds., Springer Verlag, 245-266.

Hou, A. Y., S. Q. Zhang, A. M. da Silva, W. S. Olson, C. D. Kummerow, and J. Simpson, 2001: Improving global analysis and short-range forecast using rainfall and moisture observations derived from TRMM and SSM/I passive microwave sensors. Bull. Amer. Meteor. Soc., 82, 659-680.

- G. S. Jackson, C. Kummerow, and C. M. Shepherd, 2008: Global precipitation measurement. Precipitation: Advances in Measurement, Estimation, and Prediction, S. Michaelides, Ed., Springer, 131-164.

Huffman, G. J., and Coauthors, 2007: The TRMM Multisatellite Precipitation Analysis (TMPA): Quasiglobal, multiyear, combined-sensor precipitation estimates at fine scales. J. Hydrometeor., 8, 38-55.

—, R. F. Adler, D. T. Bolvin, and G. Gu, 2009: Improving the global precipitation record: GPCP version 2.1. Geophys. Res. Lett., 36, L17808, doi:10.1029/2009GL040000.

Jiménez, C., and Coauthors, 2011: Global intercomparison of 12 land surface heat flux estimates. J. Geophys. Res., 116, D02102, doi:10.1029/2010JD014545.

Joyce, R. J., J. E. Janowiak, P. A. Arkin, and P. Xie, 2004: CMORPH: A method that produces global precipitation estimates from passive microwave and infrared data at high spatial and temporal resolution. J. Hydrometeor., 5, 487-503.

Kidd, C., and V. Levizzani, 2011: Status of satellite precipitation retrievals. Hydrol. Earth Syst. Sci., 15, 1109-1116.

—, P. Bauer, J. Turk, G. J. Huffman, R. Joyce, K.-L. $\mathrm{Hsu}$, and D. Braithwaite, 2012: Intercomparison of high-resolution precipitation products over northwest Europe. J. Hydrometeor., 13, 67-82. 
Kidder, S. Q., S. J. Kusselson, J. A. Knaff, R. R. Ferraro, R. J. Kuligowski, and M. Turk, 2005: The Tropical Rainfall Potential (TRaP) technique. Part I: Description and examples. Wea. Forecasting, 20, 456-464.

Kirschbaum, D. B., R. Adler, Y. Hong, and A. LernerLam, 2009: Evaluation of a preliminary satellitebased landslide hazard algorithm using global landslide inventories. Nat. Hazards Earth Syst. Sci., 9, 673-686.

,,--- S. Kumar, C. Peters-Lidard, and A. Lerner-Lam, 2011: Advances in landslide nowcasting: Evaluation of a global and regional modeling approach. Environ. Earth Sci., 66, 1683-1696, doi:10.1007/s12665-011-0990-3.

Knapp, K. R., and Coauthors, 2011: Globally gridded satellite observations for climate studies. Bull. Amer. Meteor. Soc., 92, 893-907.

Lettenmaier, D. P., A. de Roo, and R. Lawford, 2006: Towards a capability for global flood forecasting. WMO Bull., 55, 185-190.

Li, L., and Coauthors, 2010: WindSat global soil moisture retrieval and validation. IEEE Trans. Geosci. Remote Sens., 48, 2224-2241.

Lyon, B., and D. G. DeWitt, 2012: A recent and abrupt decline in the East African long rains. Geophys. Res. Lett., 39, L02702, doi:10.1029/2011GL050337.

Michaelides, S., V. Levizzani, E. N. Anagnostou, P. Bauer, T. Kasparis, and J. E. Lane, 2009: Precipitation: Measurement, remote sensing, climatology and modeling. Atmos. Res., 94, 512-533.

Miralles, D. G., T. R. H. Holmes, R. A. M. De Jeu, J. H. Gash, A. G. C. A. Meesters, and A. J. Dolman, 2011: Global land-surface evaporation estimated from satellite-based observations. Hydrol. Earth Syst. Sci., 15, 453-469.

Mueller, B., and Coauthors 2011: Evaluation of global observations-based evapotranspiration datasets and IPCC AR4 simulations. Geophys. Res. Lett., 38, L06402, doi:10.1029/2010GL046230.

Pan, M., H. Li, and E. F. Wood, 2010: Assessing the skill of satellite-based precipitation estimates in hydrologic applications. Water Resour. Res., 46, W09535, doi:10.1029/2009WR008290.

Reichle, R. H., R. D. Koster, G. J. M. DeLannoy, B. A. Forman, Q. Liu, P. P. Mahanama, and A. Toure, 2011: Assessment and enhancement of MERRA land surface hydrology estimates. J. Climate, 24, 6322-6338.

Simpson, J., R. F. Adler, and G. North, 1988: A proposed Tropical Rainfall Measuring Mission (TRMM) satellite. Bull. Amer. Meteor. Soc., 69, 278-295.
Sun, Y., S. Solomon, A. Dai, and R. W. Portmann, 2006: How often does it rain? J. Climate, 19, 916-934.

Tapiador, F. J., 2010: A joint estimate of the precipitation climate signal in Europe using eight regional models and five observational datasets. J. Climate, 23, 1719-1738.

— precipitation climatologies (2070-2100) as derived by eight regional climate models. J. Climate, 21, 2540-2557.

—,- , and R. Romera, 2009: Exploiting an ensemble of regional climate models to provide robust estimates of projected changes in monthly temperature and precipitation probabilistic distribution functions. Tellus, 61A, 57-71, doi:10.1111/j.16000870.2008.00374.x.

— surement: Methods, datasets and applications. Atmos. Res., 104-105, 70-97.

Trenberth, K. E., J. T. Fasullo, and J. Kiehl, 2009: Earth's global energy budget. Bull. Amer. Meteor. Soc., 90, 311-323.

Turk, F. J., and S. D. Miller, 2005: Toward improved characterization of remotely sensed precipitation regimes with MODIS/AMSR-E blended data techniques. IEEE Trans. Geosci. Remote Sens., 43, 1059-1069.

— based high resolution precipitation datasets for atmospheric composition studies in the Maritime Continent. Atmos. Res., in press, doi:10.1016/j .atmosres.2012.02.017.

Wang, J., and Coauthors, 2011: The Coupled Routing and Excess Storage (CREST) distributed hydrological model. Hydrol. Sci. J., 56, 84-98.

Wu, H., R. Adler, Y. Tian, Y. Hong, and F. Policelli, 2012: Evaluation of global flood detection using satellite-based rainfall and a hydrological model. J. Hydrometeor., 13, 1268-1284.

Xian, P., J. S. Reid, J. F. Turk, E. J. Hyer, and D. L. Westphal, 2009: Impact of modeled versus satellite measured tropical precipitation on wet removal in an aerosol transport model. Geophys. Res. Lett., 36, L16805, doi:10.1029/2009GL038823.

Yilmaz, K. K., R. F. Adler, Y. Tian, Y. Hong, and H. F. Pierce, 2010: Evaluation of a satellite-based global flood monitoring system. Int. J. Remote Sens., 31, 3763-3782, doi:10.1080/01431161.2010.483489.

Zhang, J., J. S. Reid, D. L. Westphal, N. L. Baker, and E. J. Hyer, 2008: A system for operational aerosol optical depth data assimilation over global oceans. J. Geophys. Res., 113, D10208, doi:10.1029/2007JD009065. 